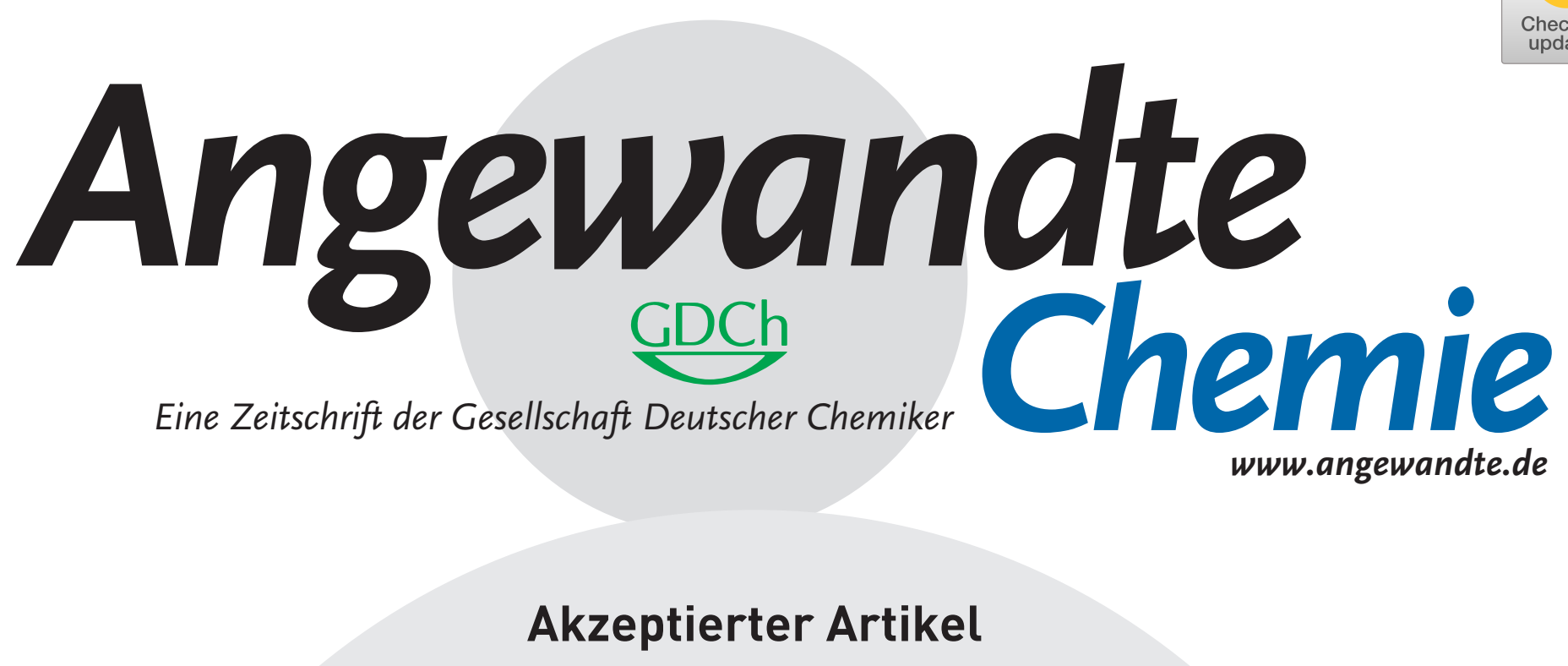

Titel: Cove-Edged Nanographenes with Localized Double Bonds

Autoren: Jishan Wu, Yanwei Gu, Rafael Muñoz-Mármol, Shaofei Wu, Yi Han, Yong Ni, María A. Díaz-García, and Juan Casado

Dieser Beitrag wurde nach Begutachtung und Überarbeitung sofort als "akzeptierter Artikel" (Accepted Article; AA) publiziert und kann unter Angabe der unten stehenden Digitalobjekt-Identifizierungsnummer (DOI) zitiert werden. Die deutsche Übersetzung wird gemeinsam mit der endgültigen englischen Fassung erscheinen. Die endgültige englische Fassung (Version of Record) wird ehestmöglich nach dem Redigieren und einem Korrekturgang als Early-View-Beitrag erscheinen und kann sich naturgemäß von der AA-Fassung unterscheiden. Leser sollten daher die endgültige Fassung, sobald sie veröffentlicht ist, verwenden. Für die AA-Fassung trägt der Autor die alleinige Verantwortung.

Zitierweise: Angew. Chem. Int. Ed. 10.1002/anie.202000326 Angew. Chem. 10.1002/ange.202000326

Link zur VoR: http://dx.doi.org/10.1002/anie.202000326

http://dx.doi.org/10.1002/ange.202000326 


\title{
Cove-Edged Nanographenes with Localized Double Bonds
}

\author{
Yanwei Gu, ${ }^{[a]}$ Rafael Muñoz-Mármol, ${ }^{[b]}$ Shaofei Wu, ${ }^{[a]}$ Yi Han, ${ }^{[a]}$ Yong Ni, ${ }^{[a]}$ María A. Díaz-García, ${ }^{[b]}$ \\ Juan Casado, ${ }^{*[\mathrm{c}]}$ and Jishan $\mathrm{Wu}^{*[a][d]}$
}

\begin{abstract}
Although a number of armchair- and zigzag-edged nanographenes (NGs) have been synthesized and studied, there are limited examples of NGs with cove-type periphery. Herein, we report efficient synthesis and electronic properties of two large-size coveedged NGs, CN1 and CN2. X-ray crystallographic analysis reveals a contorted backbone for both molecules due to the steric repulsion at the inner cove position. Noticeably, the dominant structures of these molecules contain four (for CN1) or six (for CN2) localized CC double bonds embedded in nine (for CN1) or twelve (for CN2) aromatic sextet rings according to Clar's formula, which is supported by bond length analysis and theoretical (NICS, ACID) calculations. Furthermore, Raman spectra exhibit a band associated with the longitudinal CC stretching mode of olefinic double bonds. Due to the existence of the additional olefinic bonds, both compounds show a small band gap (1.84 eV for CN1 and $1.37 \mathrm{eV}$ for CN2). They also display moderate fluorescence quantum yield (35\% for CN1 and 50\% for CN2) owing to the contorted geometry, which can suppress aggregation in solution.
\end{abstract}

The edge structure plays an important role on the electronic properties of nanographenes (NGs). ${ }^{1}$ The all-armchair-edged NGs (e.g. hexa-peri-hexabenzocoronene) can be drawn in an allbenzenoid formula without additional CC double bonds, ${ }^{2}$ and according to Clar's aromatic sextet rule, ${ }^{3}$ they are highly stable and show a large band gap. NGs with two armchair and two zigzag edges (e.g. [n]periacenes) contain less aromatic sextet rings, and usually they have a small band gap and could even show open-shell diradical character when the size exceeds a certain limit. ${ }^{4} \mathrm{NGs}$ with three zigzag edges (e.g., [n]triangulenes) always have unpaired electrons and thus they are highly reactive and hard to synthesize by solution chemistry. ${ }^{5} \mathrm{NGs}$ with four zigzag edges show properties in between the all-armchair-edged (or all-benzenoid) NGs and NGs with two zigzag edges, showing interesting optoelectronic properties suitable for organic lasing. ${ }^{6}$ All abovementioned NGs have a planar geometry. On the other hand, NGs with one or more cove-type peripheries (e.g. hexacata-hexabenzocoronene $)^{7}$ would have a contorted structure due

[a] Dr. Y. Gu, S. Wu, Y. Han, Dr. Y. Ni, Prof. J. Wu Department of Chemistry, National University of Singapore 3 Science Drive 3, 117543, Singapore Fax: (+65) 67791691 E-mail: chmwui@nus.edu.sg

[b] R. Muñoz-Mármol, Prof. M. A. Díaz-García Departamento Física Aplicada and Instituto Universitario de Materiales de Alicante, Universidad de Alicante, Alicante 03080 . Spain

[c] Prof. J. Casado

Department of Physical Chemistry, University of Malaga Campus de Teations s/n, 229071 Malaga (Spain) E-mail: casado@uma.es

[d] Prof. J. Wu

Joint School of National University of Singapore and Tianjin University, International Campus of Tianjin University, Binhai New City, Fuzhou 350207, China to the steric repulsion between the $\mathrm{C}-\mathrm{H}$ bonds at the inner cove position. This type of coved-edged NGs display different electronic properties and solid-state packing structures from the traditional planar NGs, and so far, there are only limited examples. Synthesis of large-size cove-edged NGs or graphene nanoribbons has become a challenging task. ${ }^{8}$ Herein, we report efficient synthesis of two large-size NGs CN1 and CN2 with two cove-type peripheries (Scheme 1). According to Clar's formula, the backbones of CN1/CN2 can be drawn in a form with four/six localized CC double bonds embedded in nine/twelve aromatic sextet rings (the hexagon shaded in blue colour), respectively (forms A, Scheme 1). The molecules can be also drawn in other forms with seven/ten aromatic sextets without localized double bonds (e.g. forms B, Scheme 1), which are supposed to contribute less than forms $A$ due to the loss of two sextets. The real electronic structure of this type of molecules is of interest. In addition, the cove edges will lead to a contorted structure, which may help to suppress the usually encountered strong aggregation between large-size planar aromatics. This is critical for some optoelectronic applications such as solid-state luminescence and lasing. Bulky tert-butyl or tert-octyl substituents are introduced to further improve the solubility and suppress aggregation.

The synthesis of CN1 and CN2 was mainly based on a benzannulation followed by oxidative cyclodehydrogenation strategy (Scheme 1). The precursors $(\mathbf{1 2}, 14)$ were synthesized by stepwise coupling reactions from the key intermediates, the $O$ biphenyl-/o-terphenylethynylene $(\mathbf{3}, \mathbf{5})$ and the pyrene halide/triflate $(\mathbf{8}, \mathbf{1 0})$, both requiring multiple-step syntheses. For the Sonogashira coupling between $\mathbf{3}$ and $\mathbf{8}$, or between $\mathbf{5}$ and $\mathbf{1 0}$, Fu's catalytic system $\mathrm{Pd}(\mathrm{PhCN})_{2} \mathrm{Cl}_{2} / \mathrm{P}(t-\mathrm{Bu})_{3}{ }^{9}$ turned out to be necessary to attain regio-selectivity and reasonable yields at room temperature (r.t.). $\mathrm{InCl}_{3}$-mediated alkyne benzannulation ${ }^{10}$ reaction turned out to be most efficient method for 12 and 14 among various known cyclization conditions. ${ }^{11}$ Interestingly, the cyclization went to the o-terphenyl units in 12 , while to the pyrene moiety in 14 , presumably due to different electron densities at the respective reactive sites. The structure of $\mathbf{1 3}$ was confirmed by NMR analysis, while the structure of $\mathbf{1 5}$ was deduced from the $X-$ ray structure of its analogue $(\mathbf{1 8})$ in which both $R^{1}$ and $R^{2}$ are tertbutyl groups (see Supporting Information (SI), Figure S8). Finally, Scholl-type oxidative dehydrogenation of 13 and 15 with 2,3dichloro-5,6,-dicyano-benzoquinone (DDQ) and triflic acid gave the fully fused NGs CN1 and CN2 in 30\% and 20\% yield, respectively. Both products are stable and clear ${ }^{1} \mathrm{H}$ NMR spectra were recorded in solution (see SI, Figures S37, S39, S40, S41, and S48).

Single crystals of CN1 were grown by slow solvent diffusion of methanol into a solution in toluene, while single crystals of CN2 were obtained by slow evaporation from a carbon disulfide solution. ${ }^{12}$ Both molecules exhibit a contorted skeleton, with the six benzene rings along the two cove edges bent in an alternating

Supporting Information for this article is given via a link at the end of the document. 

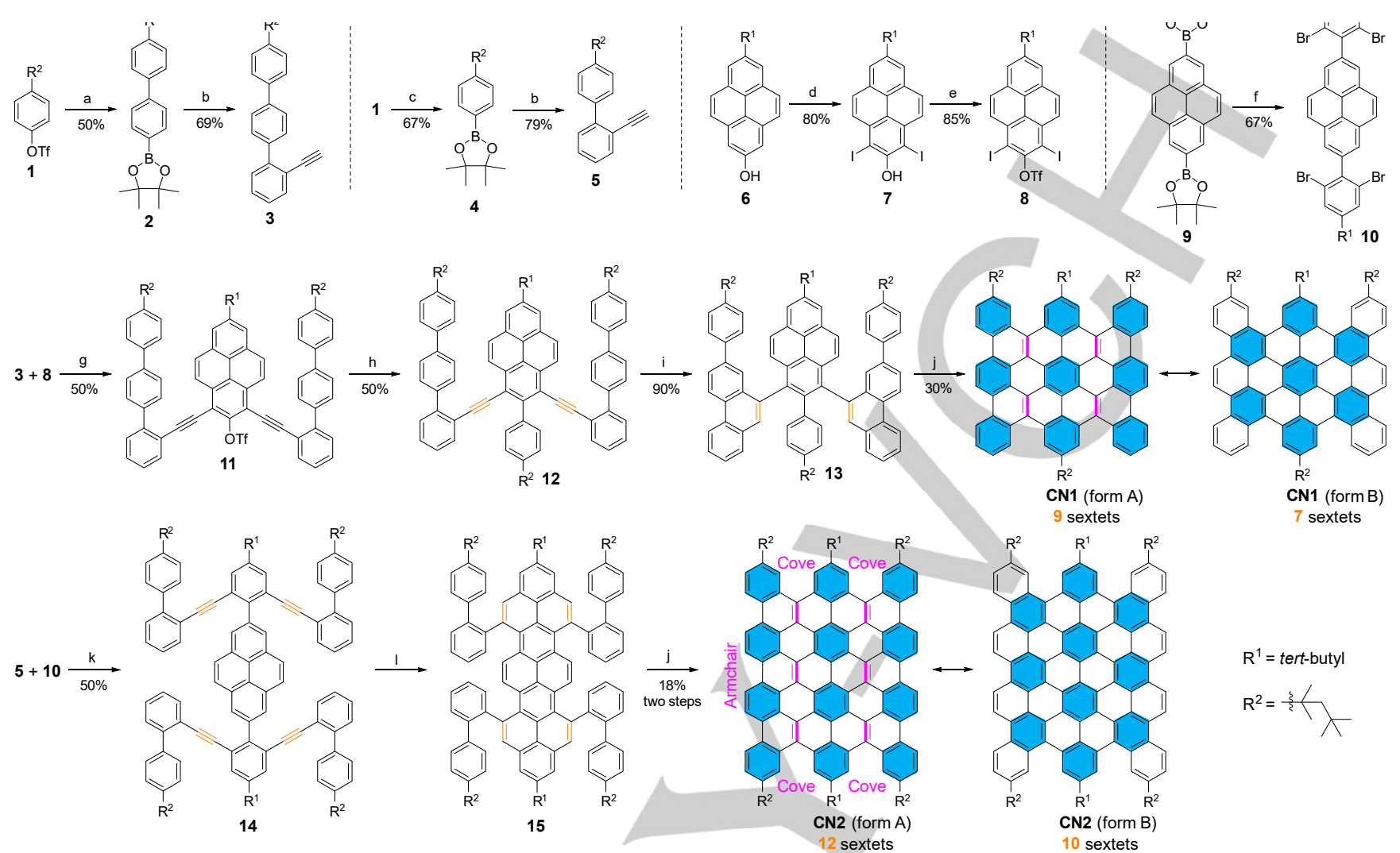

$$
\begin{aligned}
& \mathrm{R}^{1}=\text { tert-butyl } \\
& \mathrm{R}^{2}=\xi
\end{aligned}
$$

Scheme 1. Synthetic routes of $\mathbf{C N} 1$ and $\mathbf{C N} 2$ : (a) benzene-1,4-diboronic acid bis(pinacol) ester ( 3.5 equiv), $\mathrm{Pd}(\mathrm{dppf}) \mathrm{Cl}_{2}, \mathrm{~K}_{2} \mathrm{CO}_{3}, \mathrm{THF} / \mathrm{H}_{2} \mathrm{O}$, $70{ }^{\circ} \mathrm{C}$; (b) i) 2 -bromo1-(trimethylsilylethynyl)benzene, $\mathrm{Pd}\left(\mathrm{PPh}_{3}\right)_{4}, \mathrm{~K}_{2} \mathrm{CO}_{3}$, toluene/ethanol/ $\mathrm{H}_{2} \mathrm{O}, 110{ }^{\circ} \mathrm{C}$; ii) $\mathrm{K}_{2} \mathrm{CO}_{3}, \mathrm{THF} / \mathrm{MeOH}$, r.t.; (c) bis(pinacolato)diboron, $\mathrm{Pd}$ (dppf)Cl 2 , $\mathrm{KOAc}$, $\mathrm{DMF}$, $85{ }^{\circ} \mathrm{C}$; (d) $\mathrm{KI}, \mathrm{H}_{2} \mathrm{SO}_{4}, \mathrm{H}_{2} \mathrm{O}_{2}, \mathrm{MeOH}, 0{ }^{\circ} \mathrm{C}$ - r.t.; (e) trifluoromethanesulfonic anhydride, pyridine, $\mathrm{CH}_{2} \mathrm{Cl}_{2}, 0{ }^{\circ} \mathrm{C}-$ r.t.; (f) 1,3-dibromo-5-(tert-butyl)-2-iodobenzene, $\mathrm{Pd}$ (dppf) $\mathrm{Cl}_{2}, \mathrm{~K}_{2} \mathrm{CO}_{3}, \mathrm{THF} / \mathrm{H}_{2} \mathrm{O}, 80{ }^{\circ} \mathrm{C}$; (g) $\mathrm{Pd}(\mathrm{PhCN})_{2} \mathrm{Cl}_{2}$, (t-Bu) $)_{3} \mathrm{PHBF}_{4}$, Cul, toluene/i $\mathrm{Pr} 2 \mathrm{NH}$, r.t.; (h) 4, $\mathrm{Pd}\left(\mathrm{PPh}_{3}\right)_{4}, \mathrm{~K}_{2} \mathrm{CO}_{3}$, toluene/ethanol/ $\mathrm{H}_{2} \mathrm{O}, 110{ }^{\circ} \mathrm{C}$; (i) InCl 3 , mesitylene, $150{ }^{\circ} \mathrm{C}$; (j) DDQ, triflic acid, $\mathrm{CH}_{2} \mathrm{Cl}_{2}, 0^{\circ} \mathrm{C}-$ r.t.; $(\mathrm{k}) \mathrm{Pd}(\mathrm{PhCN})_{2} \mathrm{Cl}_{2}$, $(t \text {-Bu })_{3} \mathrm{PHBF}_{4}$, Cul, toluene/Et ${ }_{3} \mathrm{~N}$, r.t.; (I) ) InCl $\mathrm{In}_{3}$, toluene, $110{ }^{\circ} \mathrm{C}$.
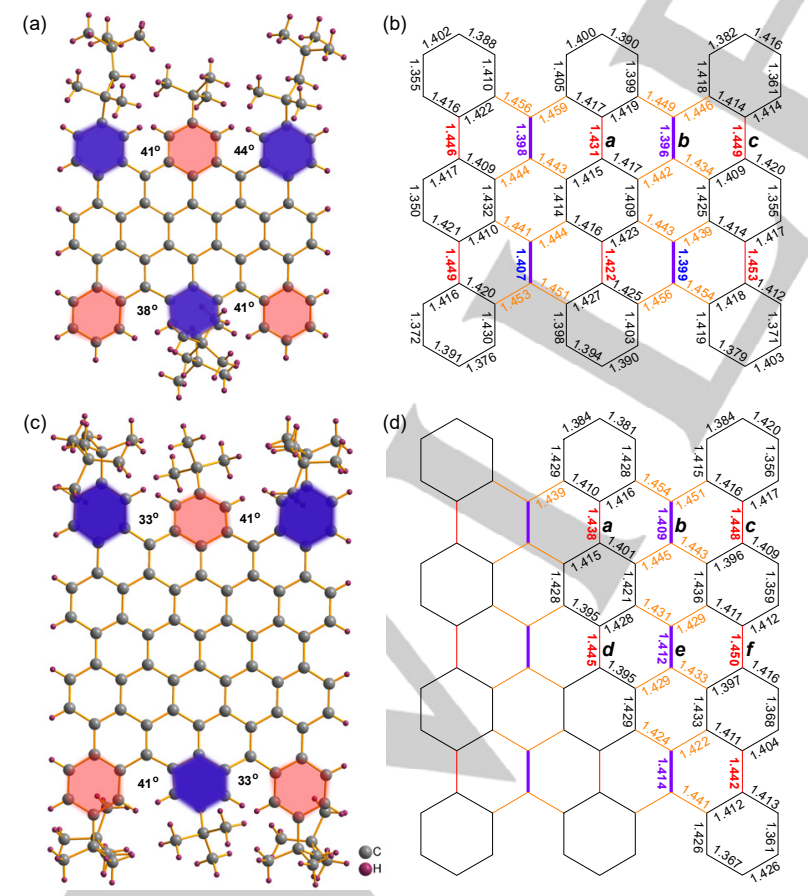

Figure 1. X-ray crystallographic structures (the benzene rings bent above and below the mean backbone plane are shaded in blue and red colour, respectively) and selected bond lengths (in $\AA$ ) of CN1 (a, b) and CN2 (c, d). up and down mode due to the steric repulsion between the $\mathrm{C}-\mathrm{H}$ bonds at the inner cove position (Figure 1a, c). The average torsional angle between the neighbouring benzenoid rings of CN1 $\left(\sim 41^{\circ}\right)$ is slightly larger than that in CN2 $\left(\sim 37^{\circ}\right)$. Although having a largely contorted backbone, the molecules of the unsymmetrically substituted CN1 still form dimers via $\pi-\pi$ stacking (mean distance: $3.4 \AA$ ), and there are close $[\mathrm{C}-\mathrm{H} \cdots \cdots \pi]$ contacts between the discrete dimers (Figure S9a in $\mathrm{SI}$ ). On the other hand, the six bulky substituents on CN2 fully suppress $\pi-\pi$ stacking and there are only intermolecular $[\mathrm{C}-\mathrm{H} \cdots \pi]$ interactions (Figure $\mathrm{S} 9 \mathrm{~b}$ in $\mathrm{SI}$ ). Bond length analysis reveals that the formally olefinic $\mathrm{CC}$ double bonds ( $b$ in CN1 and $b, e$ in CN2, highlighted in blue colour in Figure $1 \mathrm{~b}, \mathrm{~d}$ ) are in the range of $1.396 \sim 1.414 \AA$, longer than that of the typical olefins $(\sim 1.35 \AA)$. The four $\mathrm{C}-\mathrm{C}$ bonds linking each of these double bonds are much longer (1.422 1.459 $\AA$, highlighted in orange colour). Therefore, these $\mathrm{CC}$ double bonds can be considered to have a localized olefinic character. The elongation of these $\mathrm{CC}$ double bonds can be explained by i) strain induced by the steric repulsion along the cove edges, and ii) partial contribution from the form $B$ (Scheme 1). In addition, the bonds linking the longitudinal benzenoid rings ( $a, c$ in $\mathbf{C N} 1$ and $a$, $c, d, f$ in CN2, highlighted in red colour; $1.431 \sim 1.450 \AA$ ) are also much longer than these $C C$ double bonds, further supporting that both molecules have a dominant resonance form $A$. 


\section{WILEY-VCH}

\section{COMMUNICATION}

The nucleus independent chemical shift $(\mathrm{NICS})^{13}$ and anisotropy of the induced current density $(\mathrm{ACID})^{14}$ calculations were conducted to further understand the electronic structure and aromaticity of these cove-edged NGs (Figure 2). The nine (in CN1) and twelve (in CN2) aromatic sextet rings drawn in the form $A$ show largely negative $\mathrm{NICS}(1)_{\text {zz }}$ values, indicating that form $A$ indeed makes a major contribution to the electronic structures of both molecules. On the other hand, rings $B$ and $D$ in CN1 and rings $B, D, F$ in CN2 also show quite negative $\mathrm{NICS}(1)_{z z}$ values, indicating that the contribution from the from $B$ is non-negligible. The other six-membered rings have either slightly negative or positive NICS $(1)_{\mathrm{zz}}$ values, with nearly non-aromatic character. ACID plots show a dominant localized aromatic character for the nine/twelve sextet rings shown in forms $A$. However, due to the partial contribution from the forms $B$, the $\pi$-electrons can form clockwise diatropic ring currents along the outmost periphery, as well as via pathways across the inner benzenioid rings.
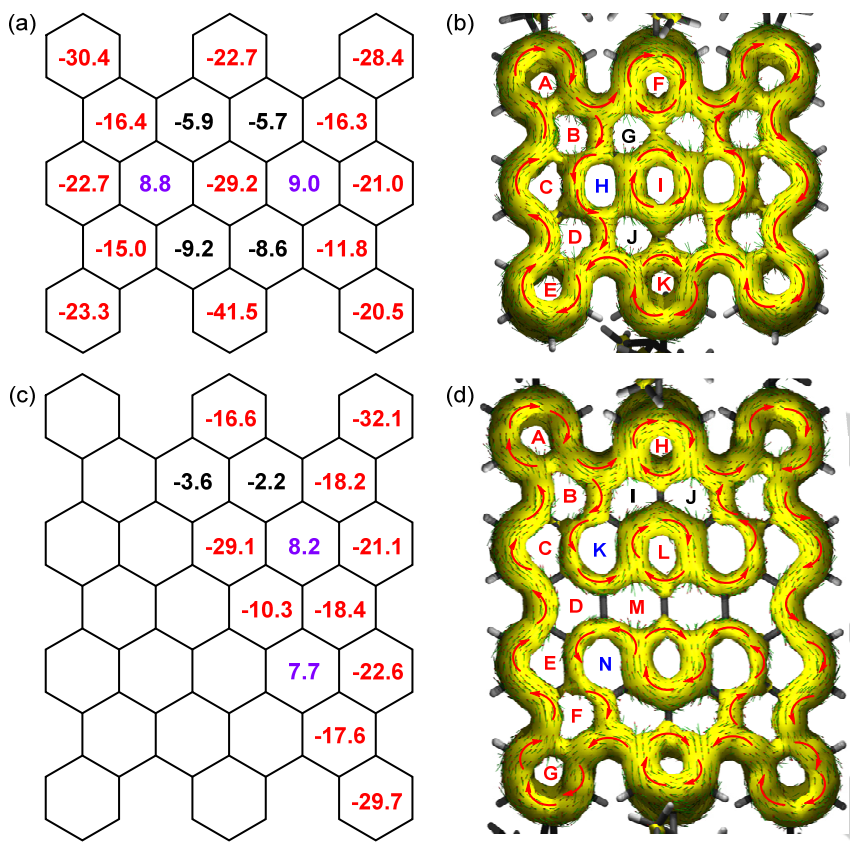

Figure 2. Calculated $\mathrm{NICS}(1)_{\mathrm{zz}}$ values and $\mathrm{ACID}$ plots (contribution from $\pi$ electrons only) of CN1 (a, b) and CN2 (c, d).

Experimental and theoretical Raman spectroscopy provided additional insight into the unique localized nature and olefinic double bond character of CN1 and CN2 (Figure 3, see full range spectra in Figure $\mathrm{S} 6$ in $\mathrm{SI}$ ). The correspondence between experimental and theoretical spectra is good and allows us to assign the Raman bands in term of vibrational normal modes from the calculated vibrational eigenvectors. There are mainly two bands around at $1611 / 1587 \mathrm{~cm}^{-1}\left(1586\right.$ and $1556 \mathrm{~cm}^{-1}$ in the theoretical spectra) and $1608 / 1590 \mathrm{~cm}^{-1}\left(1579 \mathrm{~cm}^{-1}\right.$ and $1555 \mathrm{~cm}$ 1 in the theoretical spectra) for CN1 and CN2, respectively (Figure $3 a)$. Figure $3 \mathrm{~b}$ shows the the normal modes associated with the theoretical $1586 \mathrm{~cm}^{-1}$ and $1556 \mathrm{~cm}^{-1}$ Raman bands of CN1. The band at $1586 \mathrm{~cm}^{-1}$ is due to $\mathrm{C}=\mathrm{C}$ stretching mode which spreads along the longitudinal axis ( $y$ axis) and can be termed as a "benzoquinoidal" type vibration which distinctively involves the stretching mode of the localized $\mathrm{C}=\mathrm{C}$ bond under discussion. On the other hand, the Raman band at $1556 \mathrm{~cm}^{-1}$ of CN1 corresponds to a CC stretching mode which spreads along transversal axis $(x$ axis), and it is more related to the breathing $\mathrm{CC}$ stretching mode of benzene (this mode to a less extent is also coupled to the stretching mode of the $\mathrm{C}=\mathrm{C}$ bonds). CN2 showed similar vibrational modes at $1600 \mathrm{~cm}^{-1}$ (Figure S7 in SI). Therefore, Raman spectra again support a dominant localized double bond character for both CN1 and CN2.

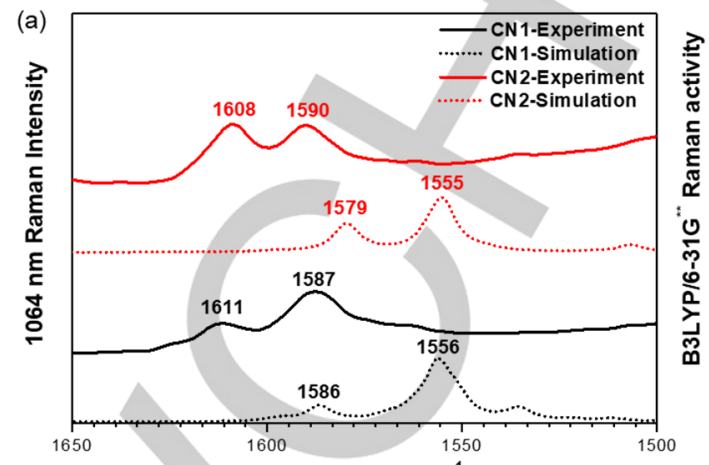

(b)

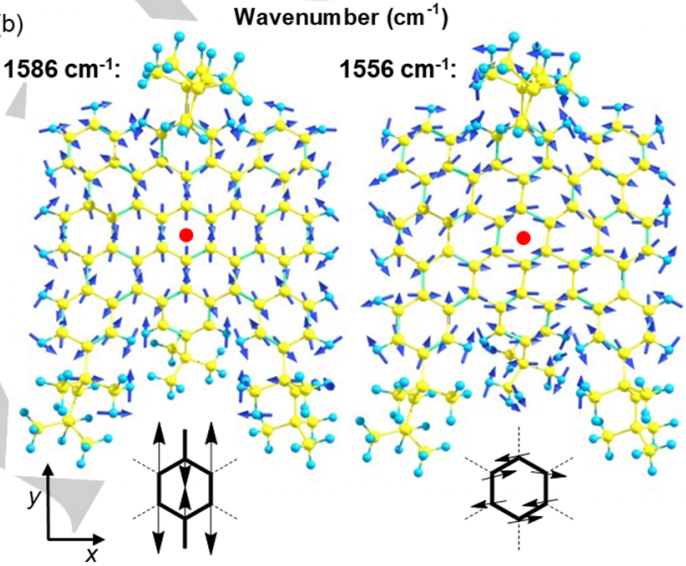

Figure 3. (a) Calculated and experimental FT-Raman spectra of CN1 and CN2 in the solid state; (b) Calculated vibrational normal mode associated with the theoretical Raman bands of CN1 at 1586 and $1556 \mathrm{~cm}^{-1}$. The vibrational modes from the central benzenoid rings are artificially highlighted at the bottom.

Compounds CN1 and CN2 in dichloromethane (DCM) both exhibit three intense and well-resolved absorption bands in the UV-vis region (Figure 4a). The longest-wavelength absorption band appears at $\lambda_{\max }=547 \mathrm{~nm}$ and $680 \mathrm{~nm}$ for CN1 and CN2, respectively, which can be assigned to a $\mathrm{HOMO} \rightarrow \mathrm{LUMO}(\mathrm{H} \rightarrow \mathrm{L})$ electronic transition according to time-dependent (TD) DFT calculations (Figures S2, S4 and Tables S2, S3 in SI). The absorption wavelengths are much longer compared to the allbenzenoid NGs with a similar size, ${ }^{2}$ which can be explained by the conjugative effect due to existence of the olefinic $\mathrm{C}-\mathrm{C}$ double bonds (i.e., rather than a limited conjugation between aromatic units). The second absorption band appears at $\lambda_{\max }=423 \mathrm{~nm}$ and $487 \mathrm{~nm}$ for CN1 and CN2, respectively, owing to a combination of both $\mathrm{H}-1 \rightarrow \mathrm{L}$ and $\mathrm{H} \rightarrow \mathrm{L}+1$ electronic transitions according to TD DFT calculations. The shortest-wavelength bands show similar red-shift with extension of conjugated skeleton, with $\lambda_{\max }=350 \mathrm{~nm}$ and $393 \mathrm{~nm}$, respectively. Compounds CN1 and CN2 in DCM both display intense fluorescence with emission maxima at 555 $\mathrm{nm}$ and $686 \mathrm{~nm}$, respectively (Figure 4a). Due to the rigid backbone, both molecules show small Stokes shifts $\left(264 \mathrm{~cm}^{-1}\right.$ for CN1, and $129 \mathrm{~cm}^{-1}$ for CN2), and moderate fluorescence quantum yields (35\% for CN1 and 50\% for CN2). The lower quantum yield for $\mathrm{CN} 1$ could be due to possible intermolecular $\pi-\pi$ stacking in solution, and larger portion of structural mobility along the cove edges. 


\section{WILEY-VCH}

\section{COMIMUNICATION}

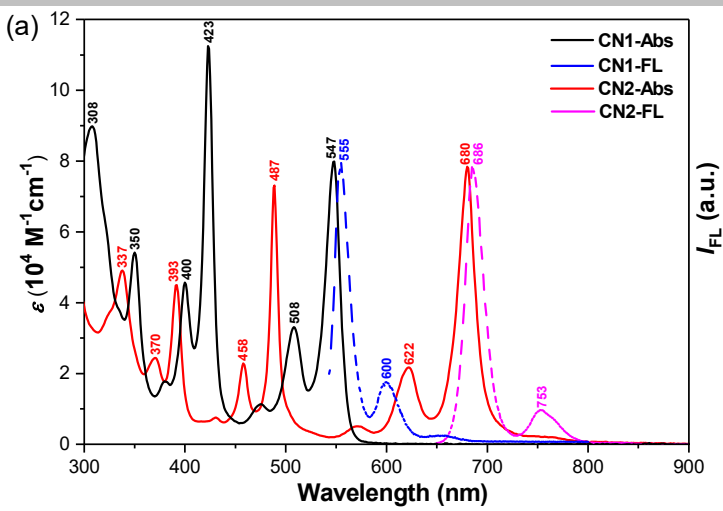

(b)

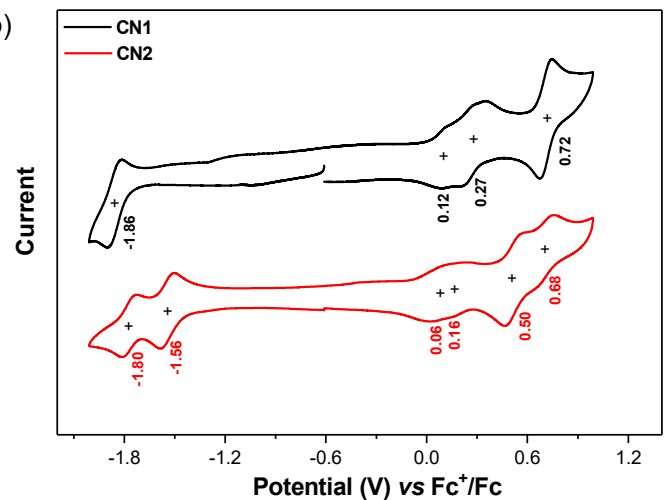

Figure 4. (a) UV-vis absorption (Abs, $c=2 \times 10^{-5} \mathrm{M}$ ) and fluorescence (FL, $c=$ $5 \times 10^{-6} \mathrm{M}$ ) spectra of CN1 and CN2 in DCM (the excitation wavelength for FL measurements is 508 and $622 \mathrm{~nm}$, respectively); (b) Cyclic voltammograms of CN1 in DCM with $0.1 \mathrm{M} \mathrm{Bu}_{4} \mathrm{NPF}_{6}$ at r.t. and CN2 in o-DCB with $0.1 \mathrm{M} \mathrm{Bu}_{4} \mathrm{NCIO}_{4}$ at $50^{\circ} \mathrm{C}$.

Compound CN1 in DCM showed three oxidation waves with half-wave potentials, $E_{1 / 2}{ }^{\mathrm{ox}}$ at $0.12,0.27 \mathrm{~V}$ and $0.72 \mathrm{~V}$ and one reduction wave with half-wave potential at $E_{1 / 2}{ }^{\text {red }}$ at $-1.86 \mathrm{~V}$ (vs $\mathrm{Fc}^{+} / \mathrm{Fc}$ ) (Figure $4 \mathrm{~b}$ ). Compound CN2 in o-dichlorobenzene (o$\mathrm{DCB})$ exhibited more oxidation waves $\left(E_{1 / 2}{ }^{\mathrm{ox}}\right.$ at $0.06,0.16 \mathrm{~V}, 0.50$ $\mathrm{V}$ and $0.68 \mathrm{~V})$ and reduction waves $\left(E_{1 / 2}{ }^{\text {red }}\right.$ at $-1.56 \mathrm{~V}$ and -1.80 V). The HOMO/LUMO energy levels were estimated to be $-4.86 /-$ $3.02 \mathrm{eV}$ for CN1 and -4.72/-3.35 eV for CN2, from the onset of the first oxidation/reduction waves. Accordingly, the electrochemical energy gap was determined to be 1.84 and $1.37 \mathrm{eV}$, respectively, in accordance with the extended T-conjugation from CN1 to CN2. Compared to the all-benzenoid NGs, ${ }^{2}$ incorporation of olefinic double bonds to the skeleton leads to higher lying HOMO energy levels and smaller energy gaps due to olefin/benzene conjugation.

In summary, two large-size cove-edged NGs CN1 and CN2 were synthesized through an efficient strategy. Both molecules have a contorted geometry due to steric repulsion along the cove edges. More importantly, such kind of topological structure confines a number olefinic double bonds in an all-benzenoid framework, which was supported by X-ray crystallographic analysis, Raman spectra, and theoretical calculations. As a consequence, the molecules show smaller energy gaps compared to the all-benzenoid NGs with a similar size. Due to the contorted geometry and substitution with bulky groups, both molecules show moderate fluorescence quantum yields, implying their potential applications in solid-state luminescence devices. Our studies provide some insight into the synthetic method and electronic properties of a new type of NGs with cove-type peripheries.

\section{Acknowledgements}

J. W. acknowleges financial support from the MOE Tier 3 programme (MOE2014-T3-1-004) and NRF Investigatorship (NRF-NRFI05-2019-0005). J.C. acknowledges MINECO and Junta de Andalucía of Spain projects (PGC2018-098533-B-I00 and UMA18FEDERJA057). M.A.D.-G. and R.M.-M. thank support from MINECO through the research project MAT2015-66586-R and the FPI fellowship (no. BES-2016-077681), respectively.

Keywords: nanographenes $\cdot$ contorted aromatics $\cdot$ cove edge $•$ aromaticity $\bullet$ optoelectronics

[1] (a) M. Fujita, K. Wakabayashi, K. Nakada, K. Kusakabe, J. Phys. Chem Jpn. 1996, 65, 1920. (b) K. Nakada, M. Fujita, G. Dresselhaus, M. S. Dresselhaus, Phys. Rev. B 1996, 54, 17954.

[2] J. Wu, W. Pisula, K. Müllen, Chem. Rev. 2007, 107, 718.

[3] E. Clar, The Aromatic Sextet, Wiley-VCH Verlag GmbH, London, 1972.

[4] (a) M. R. Ajayakumar, Y. Fu, J. Ma, F. Hennersdorf, H. Komber, J. J. Weigand, A. Alfonsov, A. A. Popov, R. Berger, J. Liu, K. Müllen, X. Feng, J. Am. Chem. Soc. 2018, 140, 6240. (b) Y. Ni, T. Y. Gopalakrishna, H. Phan, T. S. Herng, S. Wu, Y. Han, J. Ding, J. Wu, Angew. Chem. Int. Ed. 2018, 57, 9697.

[5] (a) J. Inoue, K. Fukui, T. Kubo, S. Nakazawa, K. Sato, D. Shiomi, Y Morita, K. Yamamoto, T. Takui, K. Nakasuji, J. Am. Chem. Soc. 2001 123, 12702. (b) N. Pavliček, A. Mistry, Z. Majzik, N. Moll, G. Meyer, D. J. Fox, L. Gross, Nat. Nanotech. 2017, 12, 308. (c) J. Su, M. Telychko, P. Hu, G. Macam, P. Mutombo, H. Zhang, Y. Bao, F. Cheng, Z. Huang, Z. Qiu, S. J. R. Tan, H. Lin, P. Jelínek, F. Chuang, J. Wu, J. Lu, Sci. Adv. 2019, 5, eaav7717. (d) S. Mishra, D. Beyer, K. Eimre, J. Liu, R. Berger, O. Gröning, C. A. Pignedoli, K. Müllen, R. Fasel, X. Feng, J. Am. Chem Soc. 2019, 141, 10621.

[6] (a) Y. Gu, X. Wu, T. Y. Gopalakrishna, H. Phan, J. Wu, Angew. Chem. Int. Ed. 2018, 57, 6541. (b) Y. Gu, T. Y. Gopalakrishna, J. Feng, H. Phan W. Zeng, J. Wu, Chem. Comm. 2019, 55, 5567. (c) V. Bonal, R. MuñozMármol, F. G. Gámez, M. Morales-Vidal, J. M. Villalvilla, P. G. Boj, J. A Quintana, Y. Gu, J. Wu, J. Casado, M. A. Díaz-García. Nat. Commun 2019, 10, 3327.

[7] (a) S. Xiao, M. Myers, Q. Miao, S. Sanaur, K. Pang, M. L. Steigerwald, C. Nuckolls, Angew. Chem. Int. Ed. 2005, 44, 7390. (b) X. Zhang, X. Jiang, K. Zhang, L. Mao, J. Luo, C. Chi, H. S. O. Chan, J. Wu, J. Org. Chem. 2010, 75, 8069. (c) Q. Zhang, H. Peng, G. Zhang, Q. Lu, J. Chang, Y. Dong, X. Shi, J. Wei, J. Am. Chem. Soc. 2014, 136, 5057. (d) M. Ball, Y. Zhong, Y. Wu, C. Schenck, F. Ng, M. Steigerwald, S. Xiao, C. Nuckolls, Acc. Chem. Res. 2015, 48, 267. (e) T. J. Sisto, Y. Zhong, B. Zhang, M T. Trinh, K. Miyata, X. Zhong, X.-Y. Zhu, M. L. Steigerwald, F. Ng, C. Nuckolls, J. Am. Chem. Soc. 2017, 139, 5648

[8] (a) J. Liu, B. Li, Y. Tan, A. Giannakopoulos, C. Sanchez-Sanchez, D Beljonne, P. Ruffieux, R. Fasel, X. Feng, K. Müllen, J. Am. Chem. Soc. 2015, 137, 6097. (b) Y. Li, Z. Jia, S. Xiao, H. Liu, Y. Li, Nat. Commun 2016, 7, 11637. (c) Y. Yano, F. Wang, N. Mitoma, Y. Miyauchi, H. Ito, K. Itam, J. Am. Chem. Soc. 2020, 142, 1686.

[9] T. Hundertmark, A. F. Littke, S. L. Buchwald, G. C. Fu, Org. Lett. 2000 2, 1729.

[10] R. Stężycki, M. Grzybowski, G. Clermont, M. Blanchard-Desce, D. T. Gryko, Chem. Eur. J. 2016, 22, 5198

[11] (a) A. Fîrstner, V. Mamane, J. Org. Chem. 2002, 67, 6264. (b) W. Yang, J. H. S. K. Monteiro, A. de Bettencourt-Dias, V. J. Catalano, W. A Chalifoux, Angew. Chem. Int. Ed. 2016, 55, 10427.

[12] Crystallographic data with CCDC number 1960897 (CN1), 1960898 (CN2), and 1965216 (18) are deposited in the Cambridge Crystallographic Data Centre.

[13] Z. Chen, C. S. Wannere, C. Corminboeuf, R. Puchta, P. v. R. Schleyer, Chem. Rev. 2005, 105, 3842

[14] D. Geuenich, K. Hess, F. Köhler, R. Herges, Chem. Rev. 2005, 105, 3758 


\section{Entry for the Table of Contents}

\section{COMMUNICATION}

\section{Cove-edged, contorted} nanographenes! Large-size nanographenes (see picture) with cove-type periphery and contorted structure were synthesized. They contain localized CC double bonds (highlighted in purple color) and show very different electronic structures from the all-benzenoid NGs.

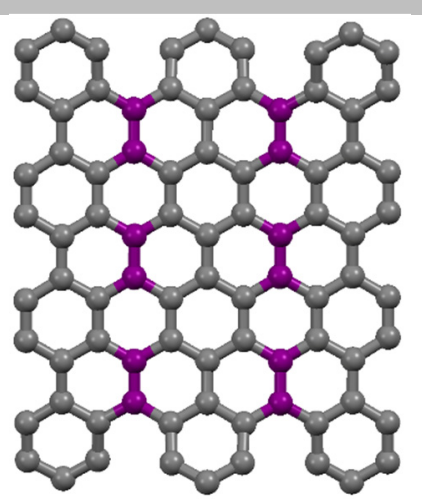

Y. Gu, R. Muñoz-Mármol, S. Wu, Y. Han, Y. Ni, M. A. Díaz-García, J. Casado, ${ }^{*}$ J. Wu $u^{*}$

Page No. - Page No.

Cove-Edged Nanographenes with Localized Double Bonds 